\title{
Vulnerabilidad, trabajo y salud en mujeres de la tercera edad en Ameca, Jalisco
}

\author{
Elderly women's vulnerability, work and health \\ in Ameca, Jalisco
}

\section{Angélica Navarro Ochoa ${ }^{*}$}

Resumen: en esta investigación se analizan las condiciones de vida de los adultos mayores, en especial de las mujeres en Ameca, Jalisco, México. Examinar su situación, desde un enfoque de género, permite mostrar la complejidad de las relaciones que construyen para enfrentar la desigualdad, el empobrecimiento y una mayor vulnerabilidad, en comparación con los hombres. El estudio es cualitativo, aunque no se descartó el análisis cuantitativo. A partir de entrevistas a profundidad, se reconstruyen experiencias de algunas adultas mayores que enfrentan desamparo, incapacidad o maltrato, y que tienen que trabajar para sobrevivir. Este trabajo contribuye a visibilizar la situación riesgosa y vulnerable de esta población, y los resultados muestran que existe una relación entre sus padecimientos y el exceso de trabajo físico que realiza. Por tanto, la condición de vida de los ancianos es vulnerable, debido a circunstancias familiares, culturales y económicas, que se reflejan en pobreza, abandono y marginalidad.

Palabras clave: mujeres adultas mayores; mujeres trabajadoras en Ameca Jalisco; vulnerabilidad social de mujeres mayores; salud en mujeres trabajadoras; interacción social en mujeres mayores.

* Profesora-investigadora. Centro Universitario de los Valles, Universidad de Guadalajara. Carretera Guadalajara-Ameca, km 45.5, C.P. 46600, Ameca, Jalisco, México. Teléfono: (375) 758-0500, extensión 47364. Correo electrónico: angelica.ochoa@profesores.valles.udg.mx 
Abstract: this research analyzes the living conditions of elderly people, especially women, in Ameca, Jalisco, Mexico. Examining their situation from a gender perspective enables us to show the complexity of the relationships constructed by them in order to face inequality, impoverishment and a greater vulnerability as compared with men. This study is qualitative, although quantitative analysis was not discarded. Based on in-depth interviews, experiences of some elder women facing abandonment, disability or battering, and who must work to survive are reconstructed. It contributes to make visible the risky and vulnerable situation of this population segment. Results show a relationship between their sufferings and their work overload. Therefore, the elderly's living conditions are vulnerable on account of family, cultural and economic circumstances, which become evident in poverty, abandonment and marginalization.

Key words: elderly women; women workers in Ameca, Jalisco; elderly women's social vulnerability; women workers' health; social interaction of elderly women.

\section{Introducción}

En las últimas décadas, los medios de comunicación, los investigadores y las instituciones internacionales y gubernamentales en distintos países han manifestado su preocupación por la situación de vulnerabilidad, marginalidad, abandono, explotación y problemas de salud que padecen los adultos mayores en el mundo. Hay quienes se atreven a decir que son "víctimas humanas de la victoria del progreso económico a escala planetaria” (Bauman 2005, 85), pues ofrecen un blanco fácil para descargar las ansiedades provocadas por los riesgos y temores de las trasformaciones sociales, económicas y familiares.

En México, el proceso de envejecimiento de la población es evidente, desde las últimas décadas del siglo xx, como resultado de la combinación de varios factores sociales y económicos que han per- 
mitido la mejora en la calidad de vida y el bienestar, junto con actitudes nuevas hacia la vida, la fecundidad y la participación de las mujeres en la sociedad; así como por los avances en la medicina y las políticas sanitarias (Ham 2003). Sin embargo, también ha generado dificultades para el cuidado y atención de los ancianos (Segalen 2007), un problema que se agrava en las localidades rurales, campesinas y con fuerte tradición migratoria, como la estudiada aquí, donde si bien existe aún la idea de que los hijos "van a cuidar y servir al padre cuando sea viejo" (Fagetti 1995), la realidad es otra.

El análisis sociocultural de este grupo etario remite al estudio de las iniquidades que inciden en las condiciones de vida del adulto mayor, ${ }^{1}$ en específico de las mujeres; ellas son proporcionalmente más numerosas que los hombres, pero también enfrentan problemáticas particulares como lo demuestran los estudios de Arber y Ginn (1995); Barbot-Coldevin (2000); Robles (2005); Navarro (2013); Mummert (2003) y McMullin (1995). La construcción sociocultural del género ha marcado diferencias entre hombres y mujeres, y son ellas las menos beneficiadas en el curso de su vida. Cuando laboran, reciben un trato diferencial, tienen salarios inferiores a trabajo igual realizado por hombres, se ocupan mayoritariamente en el mercado informal y, por tanto, no cuentan con seguridad social; cumplen jornadas dobles o triples y sus condiciones de salud y bienestar son vulnerables; su participación en la toma de decisiones es limitada, tanto en la familia como en el ámbito social en que conviven; muchas veces padecen violencia física y simbólica y, por tanto, su autonomía personal es poca, aspectos que se agravan cuando llegan a la vejez. ${ }^{2}$

Las mujeres son más longevas que los hombres y su situación se complica debido a que no gozan de una pensión o jubilación, porque nunca trabajaron en una actividad que les proporcionara seguridad

1 Con el término adulto mayor se refiere a las personas de 60 años y más, fue utilizado por la Organización Mundial de la Salud (1995) y adoptado por el Instituto Mexicano del Seguro Social (IMss) para considerar al derechohabiente en edad de jubilarse de la vida laboral. Los artículos 154 y 162 de la Ley del Seguro Social (Diario Oficial de la Federación, DOF 1995) señalan entre los 60 y 65 años para que una persona pueda jubilarse, después de cumplir los requisitos que se marcan para tal efecto. El Instituto de la Senectud y el Instituto Nacional de los Adultos en Plenitud proporcionan atención sólo a los mayores de 60 años.

2 Para algunos investigadores sociales, el concepto de vejez alude a una realidad multifacética, y la distinguen en tres edades: cronológica, social y fisiológica (Arber y Ginn 1995, 22-23). 
social; sólo se ocuparon del cuidado del hogar y de los hijos hasta que éstos conformaron sus familias, $y$ ahora que son adultas mayores esperarían la ayuda de otros para vivir la última etapa de su vida. La pregunta inmediata es ¿cómo subsisten?, ya que en ocasiones sus ingresos son limitados.

La situación general del adulto mayor es preocupante. Según el Instituto Nacional de Estadística y Geografía (INEGI 2013), en México existen alrededor de 12 millones de personas de más de 60 años, y de éstas 18 por ciento sufre de maltrato, violencia, abandono, aislamiento, discriminación, dependencia física y económica, y en la actualidad también hay factores sociales que los colocan en una posición de vulnerabilidad. Las discapacidades que vienen con la edad no les permiten ser independientes; muchas veces están desempleados o tienen un trabajo precario, con bajo salario, con jornadas que superan sus fuerzas físicas y no gozan de una seguridad social; los programas gubernamentales de asistencia social y sanitaria los benefician poco, el régimen de pensiones y jubilaciones es deficiente, y no es raro que los hijos se aparten del hogar de los padres ancianos y los visiten de forma irregular.

Ante la falta de seguridad social y el apoyo de los hijos, y como una manera de reducir los efectos de su vulnerabilidad, algunos adultos mayores se ven en la necesidad de desempeñar actividades remuneradas para sostenerse, $y$ depender de familiares o extraños para cubrir necesidades afectivas, materiales o aliviar enfermedades, como sucede entre las adultas mayores en Ameca, Jalisco. ${ }^{3}$ En México, el discurso social, gubernamental y político dice que los ancianos merecen todo el respeto de los demás, que gracias a ellos el mundo funciona en la actualidad, que la sabiduría acumulada a través de los años es insustituible y que la ancianidad merece ser el primer objetivo de cualquier intento social de bienestar; pero éste se contrapone con la

3 Ameca es una ciudad media del occidente de México, tiene una fuerte tradición migratoria no sólo hacia Estados Unidos sino también al resto del estado, principalmente hacia la zona urbana de Guadalajara y al centro turístico de Puerto Vallarta. Ubicada en la región de los valles, a $75 \mathrm{~km}$, de la capital de Jalisco, tenía 36156 habitantes: 17609 hombres y 18547 mujeres, según el INEGI (2010). La actividad productiva del lugar gira en torno al cultivo de caña de azúcar y su procesamiento en el ingenio San Francisco, desde la época porfiriana; esto facilitó el desarrollo de un flujo migratorio internacional cíclico y temporal, que se consolidó a mediados de siglo pasado con el Programa Bracero y la crisis que se vivía en el campo (Martínez 2003, 31-54). En la actualidad, el índice migratorio internacional del municipio es alto (1.05073), pero también el interno. 
realidad que vive dicha población en el país y en el mundo. De ahí se deriva el interés del trabajo por conocer las condiciones de vida de las adultas mayores amequenses; el tipo de relaciones sociales y económicas que construyen, para sobrellevar esta etapa de vida y superar las situaciones de riesgo, y el tipo de ambientes laborables y de salud que enfrentan.

La investigación está sustentada en un estudio cualitativo, que respondió al interés por analizar las condiciones de vida, trabajo y salud de las adultas mayores en Ameca. Se utilizó la entrevista a profundidad, que permitió reconstruir ciertas experiencias o momentos de la vida de ellas, identificar sus estrategias, sus formas de organización y los arreglos familiares que conforman para sobrellevar esta etapa. Se indagó y escuchó la manera de pensar, sentir y vivir de 25 personas, entre 2010 y 2013; se conocieron sus relaciones de solidaridad y de conflicto ante la toma de decisiones clave para la marcha cotidiana de su vida y del hogar, así como sus planes a "futuro". 4 En algunos casos se tuvieron que realizar dos o tres sesiones para lograr las entrevistas completas. La información obtenida se trascribió y editó para buscar mayor fluidez y dar coherencia al relato, aunque se trató de respetar el ritmo y el estilo del habla de los informantes, cuyos nombres fueron cambiados para resguardar su anonimato.

La selección de las adultas mayores para la entrevista a profundidad se hizo a partir de los casos que se consideraron representativos de una encuesta aleatoria simple, que se aplicó en los hogares de Ameca; fueron 350 cuestionarios respondidos por hombres y mujeres, en marzo de 2010, con la intención de obtener información general sobre las relaciones familiares, sus trayectorias laborales y migratorias, así como sus condiciones de salud. ${ }^{5}$

4 La guía de entrevista integró una lista de sucesos o temas como: vida familiar (matrimonio, hijos, trabajo doméstico, hogar, convivencia, distracciones); historia del trabajo femenino (empleos, salarios, seguridad social, problemáticas laborales); percepción o representaciones del ser anciano (condiciones de vida ideales y reales, preocupaciones, aspiraciones, trato, convivencia, afectividad, valoración del ser anciano); migración (familia, hijos, nietos, destinos en Estados Unidos, mercado de trabajo, problemáticas) y salud (historia de padecimientos, atención médica y problemas). Estos temas se trabajan en un proyecto de investigación de largo alcance, titulado: "Construcción social del proceso de la ancianidad en contextos laborales y migratorios", y que contó en su primer etapa con apoyo del Programa para el Desarrollo Profesional Docente. Este artículo es parte de los resultados obtenidos.

5 Con apoyo del programa spss, se organizó una muestra con cinco cohortes de individuos entre 60-65, 66-70, 70-75, 80 y más años, lo que permitió reflexionar sobre las dinámicas 
Por otra parte, la noción discursiva de género ofreció un marco analítico para comprender los relatos de vida de las entrevistadas, los cuales condensaron significados compartidos entre mujeres; aunque siempre se estuvo consciente de la heterogeneidad de casos que sintetizaron puntos de homogeneidad entre ellos.

\section{Acercamiento al estudio de los adultos mayores}

La investigación científica de los procesos de envejecimiento se consideró durante mucho tiempo competencia de la medicina; sin embargo, el aumento poblacional de los adultos mayores y sus problemáticas provocaron que en las dos últimas décadas surgiera un interés por su estudio, tanto entre los académicos de las ciencias sociales como de servidores del sector salud, quienes analizan e intentan generar propuestas que pretenden asegurar una mejor calidad de vida. Así, a los adultos mayores se les ha estudiado desde enfoques biológico-fisiológicos y también sociológicos, antropológicos, socioeconómicos, históricos, demográficos y políticos, que abordan los cambios que enfrentan, los fenómenos donde se ven involucrados y las relaciones que establecen con los demás.

Estos trabajos abonan al estudio de la ancianidad desde el enfoque micro o individualista (las teorías de la desvinculación, de la actividad, de la continuidad y del envejecimiento exitoso y productivo); también desde el macro o estructuralista (las teorías de la modernización, la económica del envejecimiento, de la estratificación etaria, paradigma del envejecimiento y sociedad y de las que vinculan los enfoques individual y estructural), hasta culminar con una combinación de estos últimos en las teorías del ciclo vital, del construccionismo social y de la economía política del envejecimiento, sin dejar a un lado el enfoque sociodemográfico. ${ }^{6}$ También se ha abordado desde las relaciones que existen entre el envejecimiento y el género, con la

y problemáticas de los adultos mayores en relación con cuestiones de género, empleo y salud, en Ameca, Jalisco.

6 Para ver a detalle estos enfoques o corrientes, consultar a Díaz-Tendero Bollain (2012, 2344). 
intención de analizar los orígenes y consecuencias de la dependencia, la discapacidad y la desigualdad entre mujeres y hombres adultos mayores (Arber y Gin 1995; Barbot-Coldevin 2000).

Las diferencias y los desequilibrios de poder basados en el género y su efecto sobre la vida de la adulta mayor han sido muy estudiados, pero aún queda algo que decir sobre todo en las condiciones sociales actuales. La agravante situación económica, la diversificación y especialización del empleo, la emigración a Estados Unidos u otras ciudades y estados de México, entre otros fenómenos, llevan a que la forma de vida de este grupo etario se complique y se evidencie la marginación y abandono de que es objeto; debido a su longevidad, necesita de más servicios médicos y cuidado de enfermedades crónicas (diabetes, hipertensión, cáncer), y por ello requiere el apoyo de la familia y de los servicios de salud. Estas circunstancias colocan al adulto mayor en una situación de vulnerabilidad social que amenaza su calidad de vida.

Las condiciones de desamparo, incapacidad, dependencia, marginación o maltrato reflejan la vulnerabilidad a que está expuesto el adulto mayor (Caro 2003). Llegar a los 60 años o rebasarlos implica ser más susceptible a sufrir algún tipo de discriminación o conducta que afecte sus intereses o a su persona (Vázquez 2013). Sin embargo, muchos de estos aspectos tienen su fundamento en la forma en que se entiende el proceso de envejecimiento.

Según el ciclo de vida, un anciano es el que alcanza la edad de 60, 65 o más años; Laslett (1996) propone las categorías de vejez y ancianidad o tercera edad o cuarta edad. ${ }^{7}$ La vejez sería la primera parte de la edad avanzada en la cual la apariencia física, las actividades y los papeles en la vida señalan un envejecimiento, pero todavía con la autonomía suficiente en términos de bienestar físico, capacidad mental, involucramiento social y economía, como para llevar una vida adecuada, independiente y con calidad. La ancianidad se caracteriza por una o varias limitantes de autonomía física, mental, social o económica, y está relacionada con el deterioro de la salud y la pérdida de capacidad social y económica, en las edades avanzadas (Ham 2003, 79).

7 Neugarten (1973) habla de joven-viejo, que va de los 65 a los 80, y de viejo-viejo, de los 80 en adelante; clasificación muy diferenciada de las otras dos. 
El resultado de estas visiones lleva al predominio de ciertos grados de convención y arbitrariedad que generan actitudes negativas sobre el envejecimiento, al considerarlo un estado en que predomina el deterioro, la enfermedad, la pasividad y la pérdida de capacidades. Sin embargo, hay casos heterogéneos con historia de vida propia y única, que permiten modificar los conceptos, las definiciones y las características dadas a lo largo del tiempo y de la geografía, y en función de la variación social, cultural y económica y siempre distinta para uno y otro sexo (Ham 2003, 60). No es lo mismo hablar de envejecimiento en mujeres que en hombres, al igual que en el ámbito rural o en el urbano; existen casos afortunados de adultos mayores que tienen gran funcionalidad física y mental, al mismo tiempo que los desafortunados, a quienes las incapacidades y enfermedades les llegan demasiado pronto; otros se retiran o se ven forzados a dejar de ser fuerza de trabajo antes de los 50 años, debido a los cambios tecnológicos o por conveniencia de los empleadores, mientras que otros permanecen activos y trabajando hasta después de los 75 años; algunos esperan ser amparados por los hijos al llegar a esta etapa, pero otros no quieren perder su independencia y autodeterminación.

Analizar estas diferencias culturales permitirá explicar el proceso de envejecimiento de las mujeres adultas mayores, que las coloca en situaciones complejas donde el maltrato, el abandono, el desempleo, la enfermedad o los abusos son comunes; pero que también las obliga a hacerles frente con recursos y capacidades de resistencia, así reconstruyen sus relaciones familiares, establecen redes sociales y de apoyo para superar sus condiciones de vulnerabilidad.

Los vínculos que ellas establecen se articulan y refuerzan con las redes de amistad, laborales y de adscripción de toda índole (religiosas, grupales, de paisanaje), y se superponen para configurar identidades inestables, fluidas y sentidos de pertenencia múltiples y cambiantes (Mouffe 2001). Esto implica la generación de condiciones para un cambio cualitativo en el capital social de las personas, que puede ser resultado de las modificaciones en la familia tradicional provocados por las trasformaciones socioeconómicas que vive la sociedad en la actualidad. 
En la década de 1990, González de la Rocha (1999); Bazán (1998) y Montes de Oca (1999) mostraron el análisis de las relaciones sociales establecidas en algunos sectores de la sociedad mexicana, para superar las amenazas que asechaban la reciprocidad familiar y el desgaste de las redes sociales debido a los efectos de las crisis económicas. Y es que las redes o los vínculos que pueden apoyar al adulto mayor, como afirmó Bourdieu (1980), no constituyen un hecho "natural" ni están constituidos de una vez y para siempre por un acto social de institución (como en la familia y sus lazos de parentes$\mathrm{co}$ ), sino que son el producto del trabajo para producir y reproducir lazos durables y útiles, que procuren beneficios materiales o simbólicos. En este sentido, la redes familiares o de otra índole no se deben ver como algo fijo, tampoco constituyen fuentes inagotables de recursos; además, no todos los sujetos pueden cultivar vínculos con la misma intensidad, puesto que se rigen por principios de confianza, solidaridad, reciprocidad y normas de acción, y quienes los conforman se benefician de ellos o los pueden romper inesperadamente al no cumplirlos (Bott 1990). Pero también estas redes pueden ser obstaculizadas, ya sea por la privación de recursos y la inseguridad económica de los individuos involucrados, por la ruptura de lazos familiares a causa de la migración y por la falta de acceso a la seguridad médica, entre otros.

Para mostrar la situación y lógica que organiza la vida de las adultas mayores amequenses, es necesario examinar las relaciones sociales que viven a partir de los 60 años. Éstas se empobrecen, con respecto al periodo de la vida anterior y, con ello, también los apoyos afectivos y económicos; muchas veces éstas se reducen a contactos interpersonales y tienden hacia una simple funcionalidad a medida que la edad avanza (Fericgla 2002, 175). No es raro que los vínculos que mantienen con los hijos, nietos o sobrinos sean instrumentales y hasta obligados; los que establecen con las instituciones formales son serios, pero faltos de sentimientos y emociones, y los que construyen con grupos religiosos, civiles o vecinos son informales, pero con importante presencia de amistad e interés que las integra a una comunidad o grupo social, además de que les permite brindar ayudas pequeñas e intercambiar afectos y bienes materiales menores (Varley y Blasco 2001). 


\section{Relaciones sociales y problemáticas de las abuelas amequenses \\ En la familia}

El grupo familiar constituye un ámbito donde conviven e interactúan personas emparentadas o no; en su seno se construyen lazos fuertes de solidaridad, se entretejen relaciones de poder y autoridad; también se reúnen y distribuyen los recursos para satisfacer las necesidades básicas de sus miembros y se definen las obligaciones, responsabilidades y derechos con arreglo a las normas culturales y de acuerdo con la edad, el sexo y la posición en relación con el parentesco de sus integrantes (González de la Rocha y Villagómez 2008; Mummert 2003; Ariza y De Oliveira 2006). Sin embargo, las trasformaciones sociales, demográficas, científicas, tecnológicas, políticas y económicas han influido de manera importante en su proceder y organización. Su magnitud disminuye (por la reproducción y la migración), con frecuencia enfrenta problemas económicos, tiende a diversificar sus ingresos y ocupaciones debido a las crisis continuas y persistentes, y con ello los ancianos pierden contactos, apoyos, solidaridades y asistencias, lo que hace que la última etapa de su vida sea compleja y esté llena de problemas.

Un ejemplo de esto es el caso de doña Lupe (2010), de 80 años y madre de seis hijos, quienes abandonaron el hogar conforme fueron creciendo, y al principio sus visitas eran constantes y disfrutó, junto con su esposo, a los nietos cuando eran pequeños, y una vez que crecieron las visitas se hicieron más esporádicas. No habían tenido la necesidad de pedir ayuda económica a los hijos, pues el esposo trabajaba como velador en un kínder, pero por su avanzada edad lo despidieron sin jubilación. Por la falta de recursos no pudieron contratar a un abogado para luchar por una pensión, y quedaron abandonados y sin dinero para mantenerse. Gracias a un antiguo conocido, a doña Lupe le facilitaron dulces a crédito, y estableció un puesto en la puerta de su casa del que hoy dependen, casi exclusivamente, para su sobrevivencia; sus hijos los visitan poco, y comentó que "cuando bien nos va, vienen una vez al mes y nos traen despensa de cosas que no podemos ya consumir, o que no nos gustan (frijoles, pastas, sardinas)." No son beneficiarios de algún programa gubernamental, y sufren penurias para alimentarse y atender sus enfermedades. 
Las adultas mayores que viven más pueden convertirse en "víctimas típicas" de maltrato y abandono familiar; sus roles domésticos no cambian con la edad, tienen que continuar haciéndose cargo del trabajo doméstico y del cuidado del esposo, y se espera que ellas cumplan con esta “obligación”, lo que no sucede con él.

En casos como el de doña Lupe, la idealización de la familia benévola se rompe; la creencia general es que ésta apoyará y cuidará a los ancianos. El gobierno da por sentado que la familia se hará cargo de las personas mayores, débiles y dependientes y les brindará los servicios básicos de salud y bienestar; también se cree que la gente casi siempre está dispuesta a ayudar a sus parientes si tienen problemas de cualquier tipo (Contreras de Lehr 1992). Por tanto, la posibilidad de que la familia deje de cuidar a los adultos mayores parece demasiado remota, sobre todo con la madre anciana, típica receptora del afecto y benevolencia familiar, y muy respetada por la sociedad en general; pero hoy es común encontrarlas viviendo solas y en condiciones económicas vulnerables. Es un hecho que la mujer vive más que los hombres, pero no siempre lo hace con una calidad de vida satisfactoria (Ham 2003; Díaz-Tendero 2009; Fericgla 2002).

En México y en otros países hay más mujeres adultas mayores que hombres; 112 por cada 100, de 60 años o más, pero 170 mujeres por cada 100 hombres de esta edad viven solas; en las zonas urbanas la situación es más grave que en las rurales, pues la proporción es de 224 por cada 100 (Varley y Blasco 2005). Algunas son viudas y no vuelven a casarse, a diferencia de los hombres. De las encuestadas en Ameca, casi una tercera parte vive sola (32.4 por ciento), esto prueba que la tendencia entre las ancianas se debe, en parte, a su propensión a tener una esperanza de vida mayor que su pareja, a que los hijos se casan o emigran, a que enviudan o no tuvieron hijos, entre otros; en cambio, si el varón queda viudo, tiene la oportunidad de casarse o sus hijos lo amparan. Hay adultas mayores que mientras les son útiles a sus hijos, ellos están cerca, pero cuando dejan de serlo las abandonan o las consideran una carga. Lucila dijo:

Mientras pude y los ayudé, ahí estuvieron, me visitaban todos los días. Mi casa siempre estaba llena, pero de un tiempo para acá, todos se han ido. Uno se fue al norte y tengo años que no lo veo, pero 
tampoco veo a los que viven aquí. Tengo un hijo que vive en La Esperanza [colonia, de la misma ciudad] y voy acabalar casi dos años sin verlo. Que se preocupen por mí ¡Qué va! Ni el diez de mayo se acuerdan que tienen madre.Y el que se acuerda, llega con un pastel que ni puedo comer porque soy diabética, los pollos son los que se lo vienen comiendo. ¿Quién me visita o me ayuda? Gente que no es nada conmigo, gente así como tú, que viene a platicar conmigo, que me ofrece apoyo y hasta alimentos (2010).

Doña Lucila, de 73 años y separada de su esposo, posee una tienda de abarrotes pequeña y ahí tiene la oportunidad de mantener relaciones con sus vecinos. No obstante estos contactos, llega a sentirse muy sola; la soledad la lleva a cuestionarse qué es lo que hizo mal para estar viviendo así, cuando no cree que lo merece, dice: "yo no me porté mal con mis padres, no sé por qué mis hijos me tratan así”. Guadalupe comentó:

Estoy aquí en el olvido por días y ni quien se acuerde de mí. Mis hijas vienen en ocasiones a visitarme y me ayudan con el quehacer, pero hasta ahí. Nadie me brinda un apoyo económico y entiendo, porque ellos tienen obligaciones con sus familias. Por eso trabajo, para no tener que pedirles nada, ni pa' mis medicinas y sí que son muchas (2011).

Rebeca expresó:

Todos están allá, ya me abandonaron aquí. Ni una carta, ni nada me escriben, tengo un hijo que no sé de él desde hace casi 10 años; los otros de vez en cuando me mandan algo, pero ni una letra me mandan. Sólo una hija, la más chica es la que no se desatiende de mí, porque de los otros tres como si ni hijos tuviera. Yo no sé qué suerte me tocó, primero viuda y hora aquí sola, abandonada en este caserón. En ocasiones creo que no voy a amanecer y temo que me van a encontrar toda engusanada, pues ni quién pregunte por mí. Sólo el trabajo y mis animales es lo que me mantiene ocupada $[\ldots]$, yo creo que la gente me juzga hasta de loca porque me la paso hablando con las plantas y los animales (2012). 
Hay otras mujeres que no quieren vivir con sus familias y prefieren quedarse en sus casas, hacer sus cosas y no las de los demás, estar tranquilas y sin reproches o regaños por no hacer las cosas bien pero, sobre todo "no les gusta ser una carga o un estorbo" o evitan tener problemas con nueras o yernos. En estas expresiones también manifestaron verdades o miedos por el cuidado de casas o nietos; de ahí que optan por vivir solas "para que nadie las moleste", "solas para no estar batallando con nueras, yernos o nietos”. Petra, viuda, de 61 años, dijo:

Sí prefiero estar aquí sola, pero en mi casa, con mis cosas, mis plantas y animales. Si me fuera con mi hija estoy segura que los problemas no tardarían en aparecer, porque mi yerno es muy codo. ¡No! Por eso aquí estoy, me levanto tarde, limpio y hago mis cosas como puedo y nadie me tiene que estar diciendo nada. Después atiendo mi negocio - da masajes en un spa- y ya por la tarde me voy al grupo, ahí me quedo hasta las 8 o 9 de la noche y hasta más. Ahora para la fiesta patronal nos quedamos en la oración hasta las 12 de la noche y cuando llegué aquí, estaba en la puerta mi hijo, muy enojado porque no estaba aquí, pero rápido le dije: ¡eh! Por eso vivo en mi casa y no en la tuya, para que nadie me diga nada [...] además de que no ando de juerga (2012).

Las adultas mayores que viven con o cerca de las familias de los hijos pueden verse obligadas a prolongar su papel de madres y amas de casa, y ya no se sienten capaces para ello, no tienen las fuerzas ni el carácter. No obstante, desempeñan el rol de padres con sus nietos, y los cuidan de tiempo completo y enfrentan sus problemáticas cotidianas: enfermedades, cuando son pequeños, y el abuso de alcohol, drogas, embarazos y rebeldías, cuando son adolescentes. Además, les ahorran a los hijos el costo de guardería o de cuidadoras, y algunas pueden apoyar a la familia con su pensión, cuando existe, u otros ingresos provenientes de remesas de hijos ausentes, de bienes o negocios propios y rentas, entre otros. Chela decía:

Sí, debo de reconocer que es muy pesado, no sabes que mal y cansada me siento en ocasiones. Siempre me he ocupado de la casa, 
crié y eduqué a cuatro hijos, así como a tres hijos de mis sobrinos que se separaron; ya ves se fueron pa' allá [a Estados Unidos] y no salieron bien, cada uno está con una pareja diferente y los hijos dados al garete; se los trajeron a mi hermana, pero ella como está [con problemas de salud] no podía cuidarlos y yo me hice cargo de ellos. Pero ahora ¡si vieras!, no puedo con mi nieto. Mi hija trabaja y me lo deja aquí, todo el día ando tras de él cuidándolo pues apenas tiene dos años y ya sabes como son. Y luego se enferma y me pongo toda preocupada y temo que mi hija me reproche que no lo cuidé bien (2012).

Los familiares suelen permanecer ajenos al tipo y grado de agotamiento que sufren las adultas mayores -sobre todo si están lejos-, tampoco están conscientes de la ayuda que les brindan para el cuidado de las casas y los nietos; les tienen poca consideración, y pretenden que sigan haciéndose cargo del hogar y de los niños, como si fueran empleadas domésticas de 20 años (Guijarro 2004). Además, ellas apoyan a los hijos en cualquier dificultad económica, y sobre todo están ahí para escuchar todos sus problemas familiares o de pareja, lo que aumenta sus preocupaciones.

En este sentido, pareciera que en la estructura familiar no se encuentran garantías de que se otorgue apoyo moral y económico al adulto mayor.Y no es que los hijos sean "malos" e "inconscientes" de la realidad que viven sus padres, sino que las condiciones socioeconómicas los obligan a depender de sus padres para el cuidado de sus hijos, realizar actividades domésticas y salir de apuros económicos.

Con el gobierno e instituciones formales

En el adulto mayor predomina la idea de que el gobierno les quita más de lo que les da. Tienen que pagar servicios e impuestos, que son onerosos pese a los descuentos, se benefician poco de las leyes o normas; su derecho a la salud es deficiente y escaso, la mayoría no goza de una jubilación o pensión que le dé seguridad social, y saben de él, sólo cuando se les quiere cobrar algo, pero poco cuando hay beneficios. Los ancianos consideran que muchos de sus apoyos son limosnas, y no un derecho ganado por sus aportaciones y trabajo de toda su vida; los ven como una forma de comprar su voto, sobre todo cuando se 
acercan las campañas electorales y se habla de programas, de ayudas y beneficios a los que pueden acceder.

Los partidos políticos consideran a los adultos mayores en sus campañas políticas por su peso electoral, además de que puede tratarse de un segmento no tan limitado como aparenta y se cree. Representan 11.9 por ciento del total, y de 2015 a 2020 superará 12.1, según las proyecciones (INEGI 2010). Es un sector que está creciendo, y no es nada despreciable para las fuerzas políticas que sustentan las votaciones locales, estatales y federales. Además, "la obligación” de votar tiene arraigo en él como "un precepto que Dios manda", como lo comentó doña Lucila (2010).

En la actualidad, la preocupación por el bienestar del adulto mayor es una actitud social más que una realidad solidaria, aunque existen acciones verdaderas en esta dirección, aún son limitadas, como el Programa 70 y Más, los del Instituto Nacional de las Personas Adultas Mayores o de Desarrollo Integral de la Familia (DIF), entre otros, que son insuficientes y criticables porque no están "todos" los que deberían, y sí muchos de los que no lo necesitan. Doña Lupe dijo:

A mí no me tomaron en cuenta, no sé cómo estuvo la cosa, pero si hay alguien necesitada aquí creo que soy una de ellas y si no, pregunte. Ahí les dieron a unas, no sé por qué si son de las más ricas de aquí. He ido con la promotora varias veces y nomás me dice: que horita no hay modo de entrar a nueva gente, pero que si no le creo vaya a las oficinas, que ella no puede hacer nada. ¿Usted cree que voy a ir?, si con trabajo puedo caminar y luego ¿quién me lleva? (2010).

Los beneficiarios de 70 y Más reciben 500 pesos mensuales -en la actualidad rebasa los 800- cada dos meses, y la cantidad se eleva cada año. Según el oficial mayor de Ameca, hasta enero de 2010 se le otorgaba a 1035 personas, cuando la población era de 3331 de 70 y más años (INEGI 2010). La ayuda es muy limitada pero, como algunos de los abuelos comentaron, "de algo a nada, es mejor algo". Este apoyo, como afirma Zemelman (1989), es un paliativo que no cura la enfermedad y, a la larga, el enfermo muere porque no se le dio el medicamento adecuado. 
A pesar de la supervivencia cultural de los valores tradicionales que obligan a respetar a los ancianos y a darles preferencias respecto a otras generaciones e individuos, y la promulgación de leyes y derechos en defensa de los grupos vulnerables, en la investigación quedó de manifiesto que los adultos mayores creen que no disponen de algún "mecanismo de poder" para defenderse en el terreno jurídico ni en el familiar. No fue raro encontrar a adultas mayores abandonadas, abusadas moral y físicamente por los extraños y también por los hijos quienes, mediante artimañas o engaños, les arrebataron los bienes que eran su patrimonio; las convencen para que les presten sus ahorros y es difícil que se los regresen; esperan a que les llegue la pensión o ayuda para quitársela y gastarla en vicios o necesidades personales; las afligen con sus múltiples problemas maritales, económicos y de salud; las apoyan poco o peor aún, las tienen en el olvido.

Los grupos religiosos y de vecinos

Hay grupos en los que el adulto mayor puede apoyarse, como en los religiosos y de vecinos. González de la Rocha (1999) documentó la importancia de la ayuda mutua entre los miembros de "constelaciones" sociales, al observar los aspectos positivos para el bienestar de quienes entablan relaciones de intercambio social, y también al descubrir que quienes carecen de ellas muestran rasgos de mucha mayor precariedad y vulnerabilidad. Su estudio demostró que el intercambio social y la capacidad de "reciprocar favores" eran cruciales para el bienestar de las familias afectadas por las crisis económicas; pero también, la falta de estos elementos o su erosión llevan a deteriorarlo, o a situaciones de mayor vulnerabilidad y carencia económica. El aislamiento social de muchas de las mujeres de Ameca las obliga a construir lazos de solidaridad y esfuerzo con la familia, si aún está ahí, pero sobre todo con vecinos, grupos religiosos y de otra índole; estos vínculos o redes les permiten sobrevivir, obtener empleos, adaptarse a circunstancias de soledad y abandono de hijos y familiares, aliviar penas y preocupaciones o salir de situaciones difíciles (económicas y de salud).

Hubo algunas adultas mayores con pocos contactos con familiares, pero sí los tenían con amigos y vecinos. Su negocio o actividad 
económica les permite construir un gran número de relaciones con clientes, vecinos y amistades, como le sucedió a Rosa, de 65 años, quien tiene una cenaduría donde vende alimentos de lunes a sábado, y que comentó:

Siempre me vez aquí en mi negocio, pues si no de qué vivo. Mis dos hijos se casaron y viven en Guadalajara, allá tienen su vida hecha y me visitan muy de vez en cuando; aquí estoy con mi marido que parece un niño, ya no sabe lo que hace, ya está grande. Eso me pasa por tonta, por haberme casado con una persona tan grande y que ahora tengo que cuidar [...]. Me siento muy sola, él está aquí pero como si ni estuviera; me la paso encerrada, nomás voy a mi mandado y estoy todo el día con mi trabajo, no tengo distracción alguna, ni amigas, pero sí muchas conocidas, clientas que llegan aquí y me entretengo con ellas, pero no les tengo la confianza para platicar mis cosas, mis problemas $[\ldots]$ no sé ni por qué te las platico a ti [empezó a llorar]. Pero es que en ocasiones me siento tan sola $[\ldots]$ y mis hijos ni se acuerdan de mí (2013).

Muchas de estas mujeres encuentran en la religión consuelo a su soledad. Ésta no sólo es un refugio para sus penas y aflicciones físicas y emocionales, o un elemento para darle significado a los fuertes cambios y trasformaciones en su vida y la de los suyos, sino que también "posee otras funciones, como la de ser un medio para 'reposicionarse' en un estatus y rol ante la sociedad; además de que las ayuda a tejer estrategias de sobrevivencia en términos de interpretación y adaptación a las cambiantes circunstancias económicas, políticas y sociales que les ha tocado vivir siendo ancianas" (Robles et al. 2006, 37). Con su colaboración en obras de caridad, en grupos de oración, de catequesis y en la promoción de eventos socializan con los miembros de su comunidad, barrio o colonia; salen de casa y conviven con sus vecinas, amigas, párrocos y religiosas; también mantienen en pie a varios grupos religiosos y a la Iglesia católica. Es común encontrar su trabajo en las fiestas patronales, en asociaciones de personas de la tercera edad que fomentan la actividad física, mental y hasta laboral. También elaboran manualidades con las que se allegan recursos y, si no, por lo menos confeccionan regalos y presentes que no comprarían para amigos y familiares. 
En sus relatos de vida, las mujeres manifestaron que en la religión y en sus representantes han encontrado las fuerzas para salir de fuertes problemas personales, emocionales y económicos. Por ejemplo, Petra (2012) vivió la primera década de su matrimonio con lujos y gran prosperidad económica, pero después de dos fracasos en los negocios del esposo, su bienestar decayó; su marido emigró a Estados Unidos y allá formó otro hogar y se desatendió de la familia que dejó en México. Petra asumió el rol de padre y madre, y sacó adelante a sus cuatro hijos, dos de ellos terminaron la carrera de medicina. Cuando el más pequeño estaba a punto de egresar, el esposo regresó y le pidió otra oportunidad, ella lo aceptó de nuevo como pareja, por sus hijos y por la idea de que el matrimonio era para toda la vida. Al poco tiempo, la mujer con quien vivió en el "norte” lo buscó y reanudaron la relación. Petra los descubrió y le pidió que abandonara la casa que ella había comprado con gran esfuerzo, no soportó una segunda traición y cayó en una fuerte depresión emocional que, según sus palabras, "casi la vuelve loca", pero encontró apoyo para superar su pena en la religión, en especial en un sacerdote quien la invitó a participar en un grupo donde recibió terapia y pudo salir adelante. Ahí mismo le ofrecieron la oportunidad de aprender un oficio; asistió a un taller de masajes holísticos, primero como paciente y después aprendió la técnica. Desde hace cinco años abrió un spa donde trabaja y enseña a adultas mayores con problemas económicos, para que puedan trabajar. Mientras tanto, ella continúa siendo una de las integrantes más activas en el grupo eclesiástico del lugar.

En Ameca, las agrupaciones relacionadas con la Iglesia están conformadas, en su mayoría, por personas adultas mayores. En los ejercicios litúrgicos y de análisis de la palabra de Dios casi dos terceras partes de los presentes son mayores. En éstas, según palabras de varias entrevistadas, encuentran consuelo y ayuda para superar los problemas cotidianos, comprender el comportamiento de hijos y nietos, y llevarlos por el "buen camino"; les inculcan un cambio de mentalidad para no sentirse "viejas", para no considerarse un estorbo y que no sirven para nada; las orientan para realizar actividades que les permiten estar activas y encontrar motivos para vivir, sobre todo cuando están solas. Decía Esperanza, de 66 años: 
Soy ministro y llevo a nuestro señor a los enfermos, y en este quehacer me doy cuenta de cuánto viejito está abandonado por sus familias o que ahí están los hijos, pero los tratan mal y como un estorbo. Tienen necesidades económicas, pero más de afecto, están enfermos y no se alivian por la soledad que sienten; la depresión los lleva a desear la muerte. Cuando veo esto, me acerco y los invito a participar en el grupo de estudio de la Biblia, algunos aceptan otros no tienen el ánimo. Aquellos que llegan al grupo, lo primero que hay que enseñarles es valorarse, a sentirse útiles y capaces de hacer todavía muchas cosas. Porque no sólo es leer la Biblia, ahí también hacemos ejercicio, aprendemos manualidades que después exponemos y vendemos aquí afuera de la iglesia, nos vamos de paseo y convivimos con otros grupos, hacemos kermeses y ayudamos a la gente necesitada. A veces estas abuelitas llegan todas apachurradas, pero en un par de meses, son otras. Ve a doña Lupita (2012).

Doña Lupita estaba muy mal cuando llegó, en ocasiones con fuertes depresiones y en otras encorajinada con el mundo y su familia por el abandono en que la tenían. Pero ahora es una de las más activas del grupo, "cambió mucho", dijo Petra: "ahora ve cómo anda, pintadita y cambiada, y con aquel ánimo que contagia”. Según Esperanza, la coordinadora, "es lo que le hace falta a muchos viejitos y aquellos no tan viejos; es hacerlos sentir que valen, que son importantes, útiles y queridos, y si esto no lo logran con su familia, aquí sí".

En Ameca existen otras instancias que también están apoyando y enfrentando las problemáticas del adulto mayor, como el DIF, que no tienen nada que ver con la religión, ni con alguna institución del gobierno. También están los grupos de costura y manualidades, que se conforman gracias a las clases de bordados y tejidos, que ofrecen algunos negocios de mercería; se detectaron siete, donde se reúnen, a media mañana o por la tarde, mujeres adultas mayores y jóvenes que aprenden alguna manualidad; ahí, entre bordado y bordado, se desahogan penas, se intercambian afectos, conocimientos, recetas de comida, remedios caseros, pero también venden sus productos. En algunos de estos negocios tienen un aparador donde ofertan sus artículos, o se organizan y los domingos lo hacen en la plaza principal. También, el gobierno municipal organiza un evento anual donde in- 
vita a empresarios y comerciantes a exponer sus negocios y productos; ahí, desde hace tres años, estas mujeres venden sus artículos y manualidades.

Asimismo, al adulto mayor lo respaldan sus vecinos, amigos, conocidos y parientes (sobrinos de segunda o tercera generación), de quienes muchas veces reciben ayuda para salir de problemas cotidianos, domésticos y superar la precariedad y vulnerabilidad en la que viven; les dan apoyo moral y emocional, los hacen sentirse parte de un grupo, de un barrio o una sociedad. Con ellos se construye simbólicamente una gran familia en donde existe un alto grado de confianza, amistad y solidaridad. Doña Lupe expresó:

Mi familia, ¿cuál?, ¿dónde está? Si no fuera por mis vecinos, no sé qué sería de nosotros, son ellos en vez de mis hijos los que están al pendiente. Esta mujer que ves aquí viene todos los días a ver qué me hace falta, qué mandado necesito o cómo amanecí. Ve, voy llegando del centro de salud y sin desayunar ni comer [eran las 5 de la tarde]. Me fui con 100 pesos que tenía, 60 del taxi de ida y vuelta, y 40 para que este hombre almorzara, porque almorzaba él o yo, pero él está más enfermo, así que él almorzó. Yo lo haré horita que esta mujer me trajo este plato de comida [...]. Pero Dios y la providencia, espero en este ratito vender algo y ya salga pa'la comida de mañana.

Las redes vecinales se convierten en los amortiguadores más eficaces de las adversidades económicas (González 2008) de los ancianos, pero también les ofrecen afecto, les permiten superar la soledad y sentirse integrados a una comunidad, a un barrio o colonia.

\section{La necesidad del trabajo en las mujeres adultas mayores}

En la sociedad actual, muchos adultos mayores carecen de una función especial; antes no se retiraban, morían en activo, pero con la industrialización y la modernización apareció el retiro y la jubilación y, con ellos, la pérdida de funciones y el cambio de rol en las relaciones familiares y laborales. Al analizar esta situación con un enfoque 
de género, "el retiro" y el trabajo de las y los adultos mayores tienen expresiones distintas. En general, cuando el hombre se retira muchas veces lo hace con una jubilación otorgada por alguna institución de seguridad social -ya sea en México o en Estados Unidos-, o bien la familia se hace cargo de él. Para la mujer "el retiro" no existe, ella continúa dedicada al quehacer doméstico en forma exclusiva o en combinación con otra actividad informal, como ocurre en Ameca.

La Encuesta nacional de la dinámica demográfica (INEGI 2009) mostró que 34 por ciento de los hombres recibían algún tipo de pensión, y sólo 17.6 de las mujeres. En el caso de estudio, 29.5 por ciento de las mayores perciben ingresos por una pensión, comparado con 70.5 de los hombres; 12.9 por ciento de este sector de la población manifestó estar apoyado por un programa de asistencia social (Oportunidades, 70 y Más y Cáritas) y 54.6 que no contaba con ayuda, ${ }^{8}$ ya que nunca desempeñó una actividad que les proporcionara una seguridad social; y ahora, en su edad adulta se ven obligados, sobre todo las mujeres, a buscar un trabajo asalariado o depender de otros para vivir -esposos, hijos o programas gubernamentales-.

Así, 60.1 por ciento de las encuestadas declaró depender económicamente del esposo o de los hijos; 33.1 era autosuficiente, porque contaba con una pensión u obtenía recursos de su actividad laboral, y sólo 3.5 dijo que rara vez dependía de alguien. Esta falta de seguridad económica las lleva muchas veces a ocuparse para obtener ingresos, pero por lo general lo hacen en el mercado informal, lo que limita el salario y su acceso a los servicios de salud.

Según los testimonios, el trabajo y el esfuerzo físico que realizan las hace sentirse útiles y acompañadas, mitigar u olvidar sus enfermedades; además, continúan desarrollando capacidades para estar activas y contribuir a la reproducción de la vida familiar. Afirman que trabajan porque "disfruto el trabajo que hago"; "por mi trabajo, soy lo que soy"; "porque me mantiene viva y en movimiento"; "porque me

El sistema de seguridad mexicano se financia mediante un impuesto sobre el sector laboral formal, pero muchas veces está sujeto a la contracción provocada por las crisis económicas. Además, las iniciativas para mantener esta seguridad muchas veces pueden entrar en conflicto con las políticas de reajuste económico, y que tienden a reducir el gasto público. De ahí que casi siempre las pensiones están desfasadas con respecto a la inflación y, por tanto, su precariedad no permite satisfacer las necesidades de los adultos mayores (Ham 2003). 
mantiene ocupada y me distrae de las preocupaciones de los hijos"; "mi trabajo es importante para mí y para mi salud". Asimismo, logran satisfacciones como: a) autoestima y amor propio; b) aceptación social y respeto por parte de los demás; c) desarrollo y satisfacción personales (reto, autonomía, satisfacción, goce, significado); d) actividad y forma de vida, antídoto contra el aburrimiento y la depresión; e) contacto social y, sobre todo, f) sentirse capaces para no depender de nadie.

El significado del trabajo cambia con la edad, lo financiero tiene peso; pero también las personas mayores le dan valor a los aspectos intangibles como la satisfacción, el logro y la amistad. Y más en esta etapa en que necesitan alientos y más satisfacciones personales que cubran vacíos emocionales, o que los distraigan de preocupaciones, amarguras o rencores.

Algunas de las adultas mayores fueron asalariadas desde una edad muy temprana, y al llegar a la adultez lo siguen siendo. Esto se debe a diversos motivos, pero algo común entre las entrevistadas es que al principio lo hicieron para sacar adelante a sus hijos y sus hogares, y después debido al abandono del esposo, por viudez, incapacidad del marido para mantener el hogar o por problemas económicos de los hijos para ayudarlas.

El cuidado y mantenimiento de los nietos es muy común en esta región, donde hay mucha emigración a Estados Unidos. Aquí la salida de individuos jóvenes-adultos parece un elemento que contribuye a que las personas mayores se ocupen del cuidado de los nietos de sus hijos migrantes, de padres separados o divorciados. Ellas vuelven a ejercer la maternidad, pero no con las energías que tuvieron para educar y cuidar a sus hijos. Y cuando no se cuenta con los recursos o no llegan remesas o apoyos, ellas tienen que buscarlos. Fue el caso de doña Guadalupe:

La pobreza es la que me tiene aquí, desde las 8 de la mañana a las 6 o 7 de la noche, llueva, haga calor o frío. No tengo quien me ayude, al contrario soy yo la que tengo que andar echándole la mano a ellos [sus hijos]. Aquí hay días que me va muy bien, saco mis doscientos pesos libres, pero hay días que todos [los elotes que vende] se me quedan y van a dar al costal para los animales, porque pa' 
otro día ya no sirven. Y cree que me va alcanzar pa' pagar mil pesos de renta y mis medicinas que tengo que estar tomando de diario pa’ el corazón. ¡No! La vida es dura, pero ni me quejo, mejor me pongo a trabajar, porque si no, nomás voy a amargarme.

Todos tienen su responsabilidad, ya me abandonaron. Ni una carta, ni nada me escriben, se fueron allá e hicieron su vida, se separaron de sus mujeres y ya viven con otra, y los hijos del primer matrimonio aquí conmigo pues ni uno ni otro se acuerda de ellos. Y si ni a ellos les escriben, mucho menos a mí, ya no se diga que me mandan un peso. Pero tampoco les pido, nomás a Dios sí le digo que me dé salud pa' trabajar y no me faltará para comer (2011).

Los ingresos de estas abuelas muchas veces no les permiten tener toda la independencia y bienestar económico que quisieran, y si a esto se suman los gastos de sus crecientes enfermedades, su situación se complica día con día, al igual que su salud física y emocional.

Abordar el tema de los adultos mayores obliga también a estudiar la relación salud-enfermedad-atención que vive el grupo etario. En esta etapa de la vida, la vejez es como un estado asociado a condiciones sociales de decrepitud, dependencia, vulnerabilidad y marginación; y donde el funcionamiento del cuerpo biológico, social, económico y político presenta señales de pérdida, declive y cercanía con la muerte (Robles 2005). En lo biológico, la funcionalidad física y mental constituyen elementos para valorar el desarrollo de sus actividades cotidianas, sus "achaques" y enfermedades crónicas. En lo económico, sus referentes se definen a partir de si gozan de una pensión, si reciben apoyos de programas sociales o de sus familias, y si no cuentan con ellos sus condiciones materiales se agravan, sobre todo cuando no se tiene acceso a una institución de salud. En lo social, se vislumbra marginalidad con respecto al intercambio de relaciones y servicios con las generaciones más jóvenes; y en lo político, se perciben como ciudadanos sin capacidad de poder para cambiar sus condiciones de vida, reclamar servicios, conocer y demandar derechos o reaccionar ante el maltrato y el abandono.

Esta situación, estudiada por Robles (2005), se presta para considerar al adulto mayor como un ser dependiente y que, por tanto, requerirá cuidado constante. Dadas las diferencias de edad al contraer 
matrimonio, los hombres tienen más probabilidad de que al sufrir una enfermedad puedan ser cuidados por su cónyuge, pues la esposa ha cumplido siempre con ese rol de género y en caso de no ser así, están sus hijos-hijas para hacerlo, pero no sucede lo mismo cuando la mujer llega a necesitar cuidados. Ella puede tender a vivir más que los esposos, pero su calidad de vida no es la ideal (Barbot-Coldevin 2000).

Las enfermedades son una amenaza continua a causa del desgaste natural de las células y del organismo, pero también son propiciadas por aspectos culturales. Con el cambio de alimentos, los hábitos y las formas de vida, es común que se llegue a padecer arteriosclerosis, osteoporosis, obesidad, diabetes, hipertensión, cáncer o depresión, junto con una constelación de trastornos físicos y psiquiátricos. Este tipo de enfermedades también pueden estar relacionadas con el aumento de las preocupaciones y tensiones, así como por el agotamiento causado por la actividad laboral superior a la que puede desempeñar un adulto mayor (Guijarro 2004).

Las mujeres estudiadas aquí sin duda tienen cargas físicas y emocionales que con frecuencia superan, en proporción, a las de los hombres, no sólo cumplen con sus responsabilidades fijas en el hogar sino que también atienden negocios, cuidan nietos, asisten a algún grupo religioso, social o político. Por ello, las quejas de cansancio y de malestares son comunes entre ellas. Pero se rehúsan a dejar dichas actividades pues, como dijo doña Lucila "no podemos estar sin hacer nada, y si terminamos lo que estamos haciendo buscamos otro quehacer" (2010).

La pobreza embarga a muchas de las abuelas entrevistadas, y su preocupación cotidiana es la obtención de recursos que les permitan sobrevivir. A ésta se suman las ocasionadas por los hijos ausentes y presentes, por sus problemas de alcohol, drogas, enfermedades, accidentes; por las dificultades económicas (la pérdida de bienes: casas, coches, servicios o desempleo) y familiares (divorcios, separaciones, infidelidades, muerte de hijos). La angustia y desesperación las lleva a un estado de nerviosismo y estrés que provoca o reactiva malestares como presión alta, ansiedad, neurosis, depresión, taquicardias o fibromialgias, que van deteriorando su salud y, con ello se hace necesaria la procuración de servicios médicos a los cuales no siempre pueden acceder. 
Estas enfermedades con frecuencia son graves y mortales, y las padecen más las mujeres que han tenido responsabilidades directas como amas de casa o un trabajo asalariado durante muchos años, y que asumen voluntariamente o son obligadas a hacerlo (Guijarro 2004, 123); éstas pueden resultar de la combinación de varios factores, que provienen de una carga física y emocional excesiva y continua, que se refleja en condiciones graves y desequilibrios progresivos tanto somáticos como psíquicos del cuerpo o del alma.

Al buscar una relación entre los padecimientos de las adultas mayores y el exceso de trabajo físico es posible suponer que sí existe, según los resultados de las 25 entrevistas y la encuesta aplicada; ya que se identificó en 15 de éstas. Las mujeres desempeñan actividades asalariadas, y tienen alguna enfermedad relacionada con las emociones y el desgaste físico. En la encuesta, 72.9 por ciento declaró padecer una, y entre las más prolíficas estuvieron la hipertensión arterial y la diabetes, que por lo general van de la mano; siguió el padecimiento de los nervios y la depresión y las relacionadas con la función motora del cuerpo: artritis, espina dorsal y rodillas, entre otras. Algunas, como Teresa, de 69 años, afirmaron que con la edad y el aumento de las preocupaciones, su salud se deterioró:

De unos años para acá los nervios me han agarrado como nunca antes. Pero es que ha sido pena tras pena. Una hija resultó madre soltera de un casado, la acepté aquí en la casa y al rato otra vez hizo lo mismo con otro casado. Todos sus hermanos se enojaron muchísimo y la corrieron de la casa, yo también estaba muy enojada, pero reflexioné y dije: qué va hacer en la calle, con qué va a mantener a los dos niños, de menos aquí [en la casa] le cuido los niños mientras ella trabaja. Tú crees, la cara me chilla de vergüenza con la gente [...]. Y luego los que están allá [en Estados Unidos], a uno lo golpeó una pandilla de cholos y lo dejaron muy mal, yo no tenía con qué ir a verlo, pero una hija me prestó, ya con calma le estoy pagando $[\ldots]$. Sólo le pido a Dios que me dé salud y trabajo, y las deudas se irán (2010).

Los adultos mayores están abrumados por sus ocupaciones y responsabilidades, asediados por sus preocupaciones; en ellos la tensión 
muscular se hace crónica en distintos lugares del cuerpo: en la mandíbula, el cuello, los hombros, el pecho, la parte superior e inferior de la espalda y las piernas (Lowen 1994, 12). Muy pocos pueden relajarse, la mayoría ni siquiera se da cuenta de la tensión; la sienten por el dolor que les causa, pero pocos imaginan que es el resultado de su manera de obrar o de autocontenerse. En algunos casos consideran que la rigidez es una señal de su fortaleza, una prueba de que son capaces de hacer frente a la adversidad, de que no se quebrantarán o cederán ante el estrés o depresión, y de que pueden tolerar el malestar y hasta la angustia.

La pregunta es ¿cómo cambiar esta situación de vulnerabilidad y riesgos que viven las y los adultos mayores?, ¿qué se está haciendo para lograrlo? Ante la poca atención de la comunidad, de los familiares y del Estado, algunas abuelas toman la batuta e intentan cambiar sus circunstancias y en el camino tratan de sumar a otras. Están activando negocios personales (clínicas de masajes, cenadurías, venta de artículos, medicina tradicional), forman parte de grupos religiosos y deportivos y de talleres de costura y bordados que intentan motivarlas para tener mejores condiciones de vida.Y, como dijo Petra:

Es imposible dejar de preocuparnos por todo lo que nos rodea, la casa, los hijos y todo lo demás, pero también depende de nosotras empezar a restarle importancia a tanto problema. Nos queda poco tiempo de vida y hay que vivirla lo mejor posible. Por eso les digo a mis compañeras que hay que dejarnos de preocuparnos por los demás y nos ocupemos de nosotras. Hay que arreglarnos, hay que salir y distraernos, ocuparnos en alguna actividad que nos guste $y$ nos deje algo $[\ldots]$ y si los demás no nos apapachan, hay que hacerlo nosotras mismas (2012).

Con acciones y actitudes como la de doña Petra se desmienten las ideas de que los adultos mayores son una carga, que su vida es triste y complicada, que están acabados y enfermos, como algunos de ellos lo piensan; muestran una capacidad de resiliencia para adaptarse a la adversidad social, económica y cultural. Hay que reconocer que ellos concentran una serie de fortalezas y conocimientos que pueden y deben ser aprovechados en su justa dimensión por el resto de la familia. Es el caso del apoyo que brindan a sus hijos en la educación y cuidado 
de nietos; en la trasmisión de valores sociales y morales; en el trabajo doméstico y con las aportaciones económicas, que aunque mínimas, permiten la satisfacción de necesidades básicas y de salud, tanto personales como del grupo familiar.

La sociedad en su conjunto tendrá que asumir el reto de responder a las expectativas de los adultos mayores, pero considerando las diferencias de género tanto en el envejecimiento fisiológico como el social, económico y político, para proporcionar una calidad de vida equitativa y satisfactoria de salud a este sector de la población.

\section{Conclusión}

Aquí se trató de no adoptar una visión polarizada -idílica y negativade la situación que viven en la actualidad los ancianos; sin embargo, es una realidad que están expuestos al desamparo, a la incapacidad, la marginación o el maltrato; viven una situación riesgosa y vulnerable, definida por circunstancias que pueden ser de índole social, cultural, económica o familiar, entre otras, y que se reflejan en pobreza, maltrato, abandono y marginalidad.

Lo que a primera vista aparenta ser una falta de atención hacia algunas adultas mayores, quizá es un indicador de falta de conciencia profunda sobre sus necesidades y derechos. Aunque hay que aclarar que no todas viven en esta situación, están solas o son dependientes económicamente. Aquí se mostraron los casos que sí enfrentan un "riesgo social" familiar, laboral o sanitario y que, vistos desde una perspectiva de género, las desigualdades e iniquidades son más graves. Se encontraron abuelas en situaciones y actitudes diversas: a) las llenas de firmeza y visión constructiva; b) otras dependientes y que tienden a la pasividad; c) las que desarrollan actitudes neuróticas o beligerantes-hostiles hacia los otros y d) algunas que se sienten aisladas, carentes de relaciones sociales y marginadas.

También hay abuelas que no encajan en los estereotipos del adulto incapaz y dependiente, que requiere de ciertos apoyos o derechos para mantener condiciones de vida aceptables. Existen las que están solas y valoran su independencia, que requieren apoyo económico para disfrutar esa condición lo más posible, sobre todo cuando viven con cantidades mínimas de dinero, insuficientes para cubrir sus gas- 
tos básicos. Hay otras que, pese a su edad, siguen trabajando y cuidando a un esposo enfermo y falto de lucidez; que necesitan mantener su negocio y seguridad para no perder el techo donde viven y aliviar sus enfermedades. También están las amparadas por los hijos, pero que necesitan vigilarse para que no sean abusadas, que no las conviertan en una criada o nana de nietos y adolescentes, pues ya no tienen las fuerzas ni el carácter para controlarlos y educarlos, y las que trabajan y necesitan protegerse para tener salarios justos y horarios adecuados a sus condiciones físicas.

El cuidado y atención del anciano debe de ser una obligación compartida con la familia, la comunidad, el empleador y el gobierno. El adulto mayor debe mantener hábitos saludables, desarrollar y proteger sus recursos económicos; la familia debe atender a sus miembros mayores, en función de sus necesidades y su situación económica; los empleadores deben ofrecer trabajos en condiciones saludables para este grupo etario; la comunidad debe desarrollar actividades productivas y recreativas que los distraigan de las preocupaciones, y el Estado proveer recursos sanitarios y sociales de calidad, para que tengan una vejez digna y sin preocupaciones.

Si bien estos pueden ser los derechos de los que debe gozar el adulto mayor muchas veces son difíciles de lograr, sobre todo ante las condiciones socioeconómicas actuales del país y de las familias. De ahí que se debe buscar que cada actor involucrado en proporcionar el bienestar a este sector de la población asuma su responsabilidad. Así ya no se presentarán casos de adultos mayores abandonados, vulnerables y marginados, sino de los que disfrutan de una calidad de vida adecuada a sus condiciones físicas y humanas.

Recibido en marzo de 2015 Aceptado en junio de 2015

\section{Bibliografía}

Arber, Sara y Jay Ginn. 1995. Relación entre género y envejecimiento. Enfoque sociológico. Madrid: Narcea Ediciones. 
Ariza, Marina y Orlandina de Oliveira. 2006. Regímenes sociodemográficos y estructura familiar. Los escenarios cambiantes de los hogares mexicanos. Estudios Sociológicos 24 (70): 3-30.

Barbot-Coldevin, Joëlle. 2000. Desigualdades basadas en el género: la adulta mayor y su mayor vulnerabilidad. Ponencia presentada en el Encuentro latinoamericano y caribeño sobre las personas de edad, Santiago de Chile: Comisión Económica para América Latina y el Caribe.

Bauman, Zygmunt. 2005. Vidas desperdiciadas. La modernidad y sus parias. Barcelona: Paidós.

Bazán, Lucía. 1998. El último recurso: las relaciones familiares como alternativa frente a la crisis. Ponencia presentada en el Congreso internacional Latin American Studies Association, Chicago.

Bourdieu, Pierre. 1980. El sentido práctico. España: Taurus Humanidades.

Bott, Elizabeth. 1990. Familia y red social. España: Taurus Humanidades.

Caro, Elizabeth. 2003. La vulnerabilidad social como enfoque de análisis de la política de asistencia social para la población adulta mayor en México. Ponencia en el Simposio viejas y viejos. Participación ciudadana e inclusión social. 51 Congreso latinoamericanista, Santiago de Chile.

Contreras de Lehr, Esther. 1992. Ageing and family support in Mexico. En Family support for the elderly: the international experience, compilado por Hal L. Kendig, Akiko Hashimoto y Larry C. Coppard, 215-223. Oxford-Nueva York-Tokyo: Oxford University Press.

Díaz-Tendero Bollain, Aída. 2012. La teoría de la economía política del envejecimiento. Un nuevo enfoque para la gerontología social en México. México: El Colegio de la Frontera Norte.

DOF. 1995. Ley del Seguro Social. 21 de diciembre. 
Fagetti, Antonella. 1995. Los cambiantes significados de la maternidad en el México rural. En Relaciones de género y transformaciones agrarias, coordinado por Soledad González Montes y Vania Salles, 301-337. México: El Colegio de México.

Fericgla, Josep María. 2002. Envejecer. Una antropología de la ancianidad. Barcelona: Herder.

González de la Rocha, Mercedes. 2008. The construction of the myth of survival. En Gender myth \& feminist fables, 45-66. Estados Unidos: Blackwell Publishing.

González de la Rocha, Mercedes. 1999. La reciprocidad amenazada. Familias de bajos ingresos en Guadalajara. En Hogar, pobreza y bienestar en México, compilado por Rocío Enríquez Rosas, 13-36. Guadalajara: Centro de Investigaciones y Formación Social, Instituto Tecnológico y de Estudios Superiores de Occidente.

González de la Rocha, Mercedes y Paloma Villagómez. 2008. ¿Encuesta o etnografía? Avances y tropiezos en el estudio del intercambio social. En Método científico y política social. A propósito de las evaluaciones cualitativas de programas sociales, coordinado por Fernando Cortés, Agustín Escobar y Mercedes González de la Rocha, 297-353. México: El Colegio de México.

Guijarro Morales, Antonio. 2004. El síndrome de la abuela esclava. Pandemia del siglo xx. Granada: Grupo Editorial Universitario.

Ham Chande, Roberto. 2003. El envejecimiento en México: el siguiente reto de la transición demográfica. México: El Colegio de la Frontera Norte, Porrúa.

INEGI. 2013. Encuesta nacional de empleo y seguridad social, México. http://www.inegi.org.mx/est/contenidos/proyectos/encuestas/ hogares/modulos/eness/eness2013/default.aspx (18 de febrero de 2015).

INEGI. 2010. Censo general de población y vivienda. INEGI. 
INEGI. 2009. Encuesta nacional de la dinámica demográfica. INEGI.

Laslett, Peter. 1996. A fresh map of life. Londres: MacMillan Press.

Lowen, Alexander. 1994. El gozo. La entrega al cuerpo y a los sentimientos. Buenos Aires: Era Naciente.

Martínez Curiel, Enrique. 2003. Hasta que la green card nos separe. México: Universidad de Guadalajara.

McMullin, Jully. 1995. Teoría de las relaciones de edad y género. En Relación entre género y envejecimiento. Enfoque sociológico, coordinado por Sara Arber y Jay Ginn, 56-70. Madrid: Narcea Ediciones.

Montes de Oca, Verónica. 1999. Relaciones familiares y redes sociales. En Envejecimiento demográfico en México: retos y perspectivas. Por una sociedad para todas las edades. México: Consejo Nacional de Población.

Mouffe, Chantal. 2001. Feminismos, ciudadanía y política democrática radical. En Ciudadanía y feminismos, compilado por Martha Lamas, 33-54. México: Instituto Federal Electoral, Desarrollo de Naciones Unidas para la Mujer.

Mummert, Gail. 2003. Dilemas familiares en un Michoacán de migrantes. En Diáspora michoacana, coordinado por Gustavo López Castro, 113-146. Zamora: El Colegio de Michoacán.

Navarro Ochoa, Angélica. 2013. Relaciones de género y trabajo femenino en dos localidades michoacanas. México: Universidad de Guadalajara.

Neugarten, B. L. 1973. Personality and aging. En Handbook of psychology of aging, compilado por J. E. Birren y K.W. Schaie. Nueva York: Van Nostrand.

Robles Silva, Leticia. 2005. Relación cuidado y envejecimiento: entre la sobrevivencia y la devaluación. Papeles de Población (45): 49-69. 
Robles Silva, Leticia, Felipe Vázquez Palacios, Laureano Reyes Gómez e Imelda Orozco Mares. 2006. Miradas sobre la vejez. Un enfoque antropológico. México: El Colegio de la Frontera Norte, Plaza y Valdés.

Segalen, Martine. 2007. El parentesco en la antropología actual: de las sociedades 'exóticas' a las sociedades 'modernas'. En Familias mexicanas en transición, compilado por David Robichaux, 39-58. México: Universidad Iberoamericana.

Varley, Ann y Maribel Blasco. 2001. ¿Cosechan lo que siembran? Mujeres ancianas, vivienda y relaciones familiares en el México urbano. En Proceso sociales, población y familia. Alternativas teóricas y empíricas en las investigaciones sobre la vida doméstica en México, compilado por Cristina Gomes, 301-322. México: Facultad Latinoamericana de Ciencias Sociales, Porrúa.

Vázquez Campeo, Lucía Angélica. 2013. Sexualidad y vejez. Una realidad que se omite. En Discriminación y violencia. Sexualidad y situación de vulnerabilidad, coordinado por Edith Peña y Lilia Hernández, 201-210. México: Instituto Nacional de Antropología e Historia.

Zemelman, Hugo. 1989. De la historia de la política. La experiencia de América Latina. México: Siglo XXI, Universidad de las Naciones Unidas de México. 